\title{
Uji Sensoris Minuman Kulit Buah Naga (Hylocereus costaricensis)
}

\author{
The Sensory Test of Dragon Fruit (Hylocereus costaricensis) Peel Drink
Netty Maria Naibaho*, Samarida Munthe, Elisa Ginsel Popang, Ahmad Zamroni
Program Studi Teknologi Hasil Perkebunan, Politeknik Pertanian Negeri Samarinda, Samarinda, Indonesia
*Correspondence Author: maria_nethy@yahoo.com

\begin{abstract}
ABSTRAK
Pemanfaatan kulit buah naga sering terabaikan karena masyarakat hanya mengkonsumsi isi buahnya saja. Tujuan penelitian untuk mengetahui nilai kadar air dan tingkat kesukaan panelis terhadap minuman kulit buah naga. Penelitian ini dilakukan secara ekperimental menggunakan rancangan acak lengkap dengan dua faktor dimana faktor pertama adalah suhu pengeringan $\left(40^{\circ} \mathrm{C}\right.$ dan $\left.60^{\circ} \mathrm{C}\right)$ dan faktor kedua adalah lama pengeringan ( 6 jam, 12 jam dan 24 jam) masing-masing 3 kali ulangan. Parameter yang diamati adalah kadar air dan uji organoleptik yang meliputi warna, aroma dan rasa (skala hedonik). Hasil penelitian menunjukkan bahwa kadar air yang paling tinggi terdapat pada pengeringan dengan suhu $40^{\circ} \mathrm{C}$ dengan waktu 6 jam $(37,22 \%)$ sedangkan kadar air yang terendah terdapat pada pengeringan dengan suhu $60^{\circ} \mathrm{C}$ dengan waktu 24 jam $(3,17 \%)$. Hasil uji organoleptik menunjukkan nilai kesukaan tertinggi yaitu pada penggunaan suhu $60^{\circ} \mathrm{C}$ dengan waktu 12 jam untuk warna $(3,82)$, rasa $(3,44)$ serta aroma $(3,51)$. Sedangkan nilai kesukaan panelis terendah terdapat pada perlakuan pengeringan dengan suhu $40^{\circ} \mathrm{C}$ dan menggunakan waktu 6 jam warna $(2,62)$, aroma $(2,42)$ dan untuk rasa $(2,27)$. Kadar air minuman kulit buah naga yang terendah sudah memenuhi standart yaitu $12 \%$. Uji organoleptik panelis sangat munyukai minuman kulit buah naga (Hylocereus Costaricencis).
\end{abstract}

Kata Kunci: Kulit buah naga, kadar air, pengeringan, uji organoleptic

\begin{abstract}
Utilization of dragon fruit peel is often neglected because people usually consume only the flesh of the fruit. This study aims to determine the moisture content and the level of panelist's preference for dragon fruit peel drink. This experiment was conducted by using a complete randomized design with two factors where the first factor was drying temperature $\left(40^{\circ} \mathrm{C}\right.$ and $\left.60^{\circ} \mathrm{C}\right)$ and the second factor was drying time (6 hours, 12 hours and 24 hours), each factor was repeated 3 times. The parameters observed were moisture content and organoleptic test which included color, flavor and taste (hedonic scale). The results of this study showed that the highest moisture content was found at drying temperature of $40^{\circ} \mathrm{C}$ with drying time of 6 hours (37.22\%) while the lowest water content was at $60^{\circ} \mathrm{C}$ for 24 hours (3.17\%). The result of organoleptic test showed the highest preference value at $60^{\circ} \mathrm{C}$ with 12 hours for color (3.82), flavor (3.44) and aroma (3.51), respectively. The lowest panelist preferences were found in the drying treatment at $40^{\circ} \mathrm{C}$ and used 6 hours of color (2.62), aroma (2.42) and for flavor (2.27), respectively. The lower water content of dragon fruit peel has fulfilled the standard of $12 \%$. Moreover, the results of organoleptic test showed that panelist very liked fruit peel drink (Hylocereus costaricencis).
\end{abstract}

Keywords: Dragon fruit peel, moisture, drying, organoleptic test

\section{PENDAHULUAN}

Pangan merupakan salah satu faktor penting dalam memenuhi kebutuhan sumber gizi pada manusia. Salah satu cara yang dilakukan adalah dengan banyak mengkonsumsi buah-buahan dan sayuran. Jenis buah dan sayuran di Indonesia sangat beragam karena merupakan Negara tropis. Kebutuhan dalam 
mengkonsumsi buah-buahan dan sayuran yang tinggi dapat membantu proses pencernaan, karena buah-buahan dan sayur-sayuran memiliki kandungan gizi seperti mineral, vitamin dan beberapa enzim yang merupakan penyuplai utama dari serat dan mikronutrient yang berperan penting dalam pencernaan. Salah satu buah yang sering dikonsumsi oleh masyarakat adalah buah naga. Buah ini banyak mengandung gizi dan vitamin yang sangat berfungsi bagi tubuh, kandungan gizi secara umum yang ditemukan dalam buah ini adalah berupa potassium, ferum, serat, kalsium dan sodium. Bukan hanya buahnya saja yang berkhasiat, tetapi khasiat juga ditemukan pada daun dan kulit buah naga maka dari itu sangat disayangkan apabila kulit buah naga yang memiliki khasiat tidak dapat digunakan sebagai bahan tambahan dalam makanan dan juga kecantikan (Wahyuni, R., 2010). Dalam dunia pangan kulit buah naga ini dapat diolah menjadi selai dodol dan juga dijadikan sebagai pewarna makanan. Dalam hal penggunaannya kulit dari buah naga ini akan dihaluskan lalu diambil sarinya kemudian akan dicampurkan dengan bahan pangan yang hendak diberikan warna.

Minuman merupakan minuman berkafein yang diolah dengan cara menyeduh bagian pucuk atau tangkai daun yang telah dikeringkan. Pada umumnya minuman disajikan dalam bentuk potongan daun kering (tubruk), serbuk dan kantong celup (Putri, 2014). Beberapa jenis minuman yang beredar di masyarakat adalah minuman hitam, minuman oolong, minuman hijau, dan minuman putih. Inovasi bahan dasar minuman mulai berkembang, seperti bahan minuman dari kelopak bunga krisan, buah, rempah-rempah, kelopak bunga camomile, dan daun sirsak mulai banyak dijumpai. Dari beberapa jenis minuman yang sudah ada di masyarakat belum banyak yang mengetahui bahwa kulit buah naga juga dapat dimanfaatkan sebagai minuman seperti minuman. Penelitian ini bertujuan untuk mengetahui nilai kadar air dan tingkat kesukaan panelis terhadap minuman kulit buah naga.

\section{METODE PENELITIAN}

\section{A. Bahan dan Alat Penelitian}

Alat yang digunakan dalam penelitian ini antara lain: pisau, baskom, aluminium foil, talenan, plastik, spatula, oven, timbangan analitik, timbangan digital, desikator, mortal, sealer, sarung tangan, kain lap, masker, kamera (alat dokumentasi), kertas dan alat tulis. Bahan yang digunakan dalam penelitian ini antara lain: kulit buah naga dan air bersih.

\section{B. Prosedur Kerja}

Penelitian ini dilaksanakan di Laboratorium Pengolahan Hasil Perkebunan dan laboratorium Kimia Analitik, Prodi Teknologi Pengolahan Hasil Perkebunan, Politeknik Pertanian Negeri Samarinda selama kurang lebih 2 bulan, meliputi persiapan bahan dan alat, penelitian utama, pengambilan data dan pembuatan laporan.

\section{Pengambilan Sampel}

Sampel dibeli dari pasar tradisional segiri Samarinda. Ukuran, warna, bentuk, serta umur dari buah naga diseragamkan untuk mendapat sampel yang homogen.

\section{Pengecilan ukuran}

Kulit Buah naga dikupas lalu dibersihkan supaya terhidar dari kotoran. Daging buah naga dipisahkan dengan kulitnya. Lalu kulit buah naga di iris-iris tipis-tipis dengan ukuran $2 \times 3 \mathrm{~cm}$ menggunakan pisau stainless.

\section{Pengeringan}

Kulit buah naga yang sudah diiris tipis tadi dikeringkan menggunakan oven dengan suhu $40^{\circ} \mathrm{C}$ dan $60^{\circ} \mathrm{C}$ selama 6,12 , dan 24 jam. Setelah kulit buah naga dikeringkan kemudian di bungkus dengan aluminium foil dan plastik lalu di sealer.

\section{Penentuan Kadar Air}

Sampel diambil sebanyak 1-2 ml. Lalu dikeringkan dalam oven dengan suhu $105^{\circ} \mathrm{C}$ selama 6 jam. Didinginkan dan diukur kembali sampel. Dihitung dengan rumus:

Kadar air $=\frac{\text { Berat awal }- \text { Berat akhir }}{\text { Berat awal }} \times 100 \%$ 


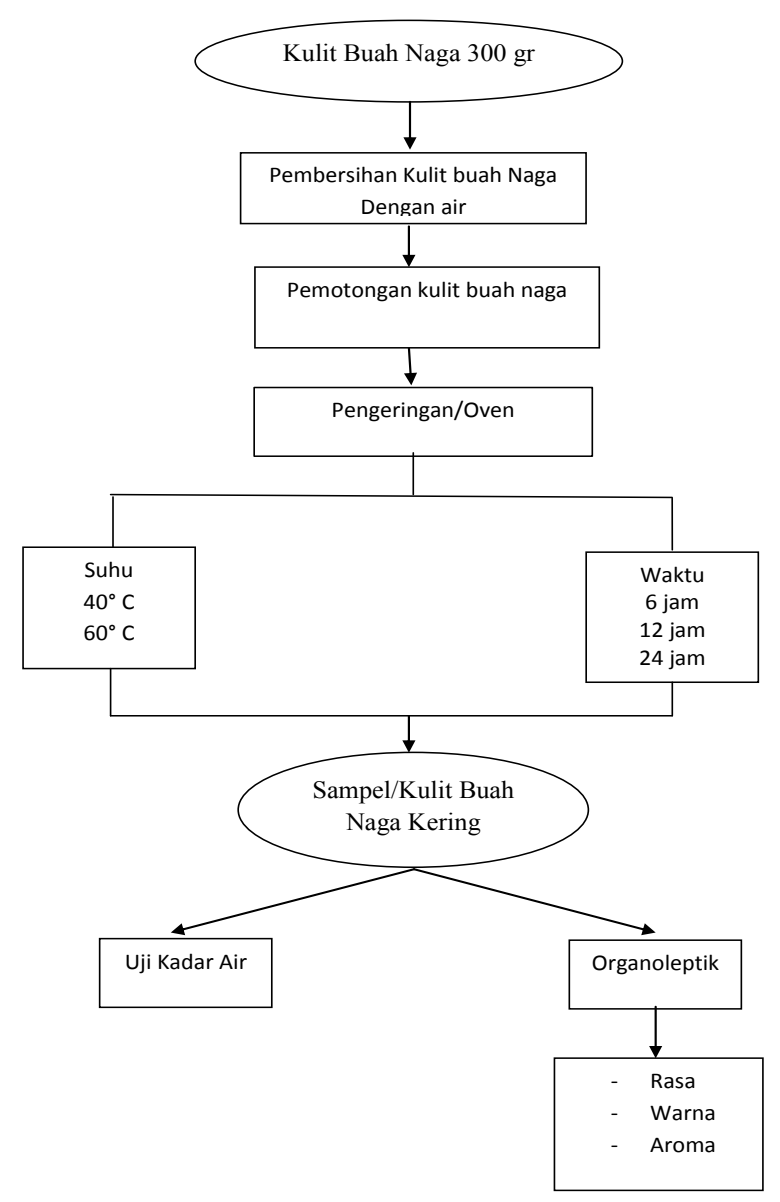

Gambar 1. Diagram Alir Pengolahan Minuman dari Kulit Buah Naga (Hyloricereus Costaricencis)

\section{Uji Organoleptik}

Masing-masing sampel diletakan didalam gelas. Setiap sampel disajikan ke dalam gelas berbeda yang diberi kode dengan angka yang berbeda-beda untuk setiap sampel. Panelis melakukan pengujian secara inderawi yang ditentukan berdasarkan skala numerik. Yaitu sangat suka nilai 4 , suka nilai 3 , agak suka nilai 2 , dan tidak suka nilai 1 . Pengujian organoleptik dilakukan terhadap warna, aroma, dan rasa pada sampel dan menuliskan respon panelis pada kuisioner yang telah disediakan.

\section{Rancangan Percobaan}

Penelitian ini menggunakan metode Rancangan Acak Lengkap factorial (RAL) Faktor $A$ adalah Suhu Pengeringan yaitu $40^{\circ} \mathrm{C}$ dan $60^{\circ} \mathrm{C}$, dan faktor $\mathrm{B}$ adalah waktu pengeringan yaitu 12 jam, 16 jam dan 24 jam. Dimana setiap perlakuan diulang sebanyak 3 kali.

\section{HASIL DAN PEMBAHASAN}

\section{A. Nilai Kadar air}

Hasil penelitian menunjukkan pengaruh suhu dan lama pengeringan terhadap kadar air suatu bahan pangan dapat dilihat pada gambar 2 .

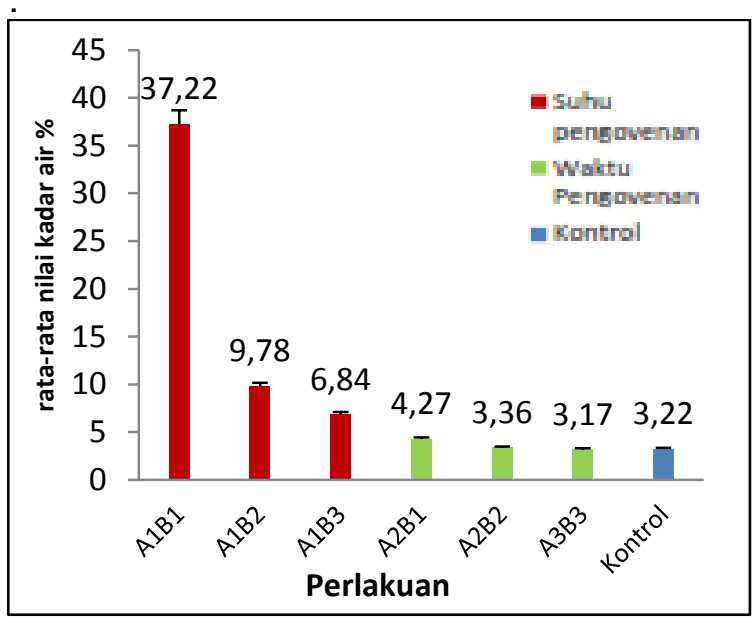

Gambar 2. Grafik Rata-Rata Kadar Air Minuman Kulit Buah Naga (Hylocereus Costaricencis) dengan Beberapa Perlakuan setelah Dikeringkan Menggunakan Oven selama 6 Jam, 12 Jam dan 24 Jam serta Menggunakan Suhu $40^{\circ} \mathrm{C}$ dan $60^{\circ} \mathrm{C}$.

Berdasarkan grafik diatas menunjukkan rata-rata nilai kadar air minuman kulit buah naga yang telah diuji kadar airnya dari yang terendah sampai dengan yang tertinggi yaitu dari 37,22\%$3,17 \%$. Kadar air yang memiliki nilai terendah yaitu suhu $60^{\circ} \mathrm{C}$ menggunakan waktu 24 jam $(3,17 \%)$ dan kadar air pada perlakuan ini sudah sesuai dengan SNI minuman the secara umum yaitu $12 \%$. Suhu dan waktu sangat berpengaruh terhadap proses penurunan kadar air. Kadar air merupakan pemegang peranan penting dalam daya simpan suatu bahan pangan, karena air dapat mempengaruhi penampakan, tekstur, dan cita rasa pada bahan pangan (Wulandari, 2016). Semakin banyak kadar air yang terkandung dalam suatu bahan pangan maka daya simpan bahan pangan tersebut akan semakin singkat. Pada proses pengeringan, air yang terkandung dalam bahan tidak dapat seluruhnya diuapkan Kusumah dan Andarwulan, 1989. Oleh karena itu, kita harus mengetahui kandungan air dalam suatu bahan pangan agar dapat 
memprediksikan umur/daya simpan bahan pangan tersebut. Kadar air yang memiliki nilai tertinggi yaitu pada pengeringan $40^{\circ} \mathrm{C}$ dan dengan waktu 6 jam $(37,22 \%)$. Semakin rendah suhu dan semakin singkat waktu yang perlakuan dalam proses pengeringan maka kadar air akan semakin tinggi. Menurut Naibaho, dkk 2009 menyatakan semakin rendah suhu pengeringan maka kadar air yang dihasilkan akan semakin meningkat. Labuza (1970) menambahkan suhu akan mempengaruhi gerakan molekul air. Apabila Aw konstan, kenaikan suhu akan mengurangi jumlah air yang terserap. Jika kadar air suatu bahan pangan tinggi maka bahan pangan tersebut akan semakin cepat rusak atau busuk. Kerusakan bahan makanan pada umumnya merupakan proses mikrobiologis, kimiawi, enzimatik atau kombinasi antara ketiganya (Tabrani, 1997 dalam Romadhon, dkk, 2014).

\section{B.Uji Organoleptik Warna}

Berdasarkan hasil uji organoleptik warna dari tingkat kesukaan (skala Hedonik) yang dipilih panelis (15 panelis). Panelis yang dipilih yaitu panelis semi terlatih. Panelis semi terlatih adalah panelis yang sudah pernah mendapatkan pelajaran tentang uji organoleptik. Masing-masing perlakuan dan ulangan pada minuman kulit buah naga dapat dilihat pada gambar 3 .

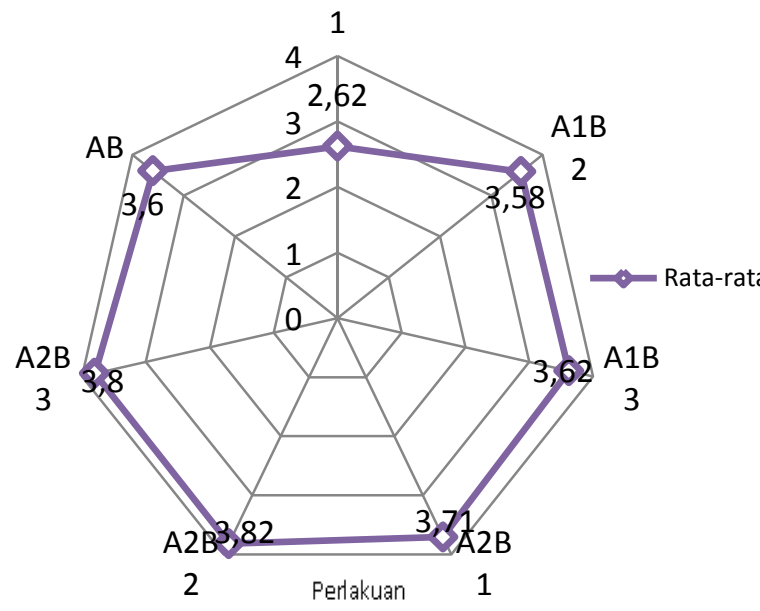

Gambar 3. Grafik Rata-Rata Penilaian Panelis Terhadap Warna Minuman Kulit Buah Naga (Hylocereus costaricencis) dengan Beberapa Perlakuan setelah Dikeringkan Menggunakan Oven selama 6 Jam, 12 Jam dan 24 Jam serta Menggunakan Suhu $40^{\circ} \mathrm{C}$ dan $60^{\circ} \mathrm{C}$.
Gambar 3. Grafik menunjukkan ratarata tingkat kesukaan panelis terhadap warna minuman kulit buah naga yang telah diseduh yaitu berkisar antara 2,62-3,82 yang berarti tidak suka sampai dengan suka. Warna yang paling disukai panelis dari hasil uji organoleptik yang dilakukan adalah pengeringan dengan suhu $60^{\circ} \mathrm{C}$ waktu 12 jam dengan nilai 3,82. Warna pada makanan merupakan salah satu faktor yang mempengaruhi daya terima terhadap makanan yang disajikan. Menurut Trisia, dkk. 2016 kesukaan terhadap makanan mencakup dua aspek utama yaitu penampilan makanan (besar porsi, warna dan bentuk makanan) sewaktu dihidangkan dan rasa makanan (aroma, bumbu, kematangan, dan tekstur) sewaktu dimakan. Kedua aspek itu sama pentingnya untuk diperhatikan agar betulbetul dapat menghasilkan makanan yang disukai masyarakat (Trisia, dkk, 2016).

Rata-rata kesukaan panelis terendah terhadap warna minuman kulit buah naga terdapat pada pelakuan $A_{1} B_{1}$ ulangan kedua menggunakan suhu $40^{\circ} \mathrm{C}$ dan waktu 6 jam dengan nilai yaitu 2,62. Hal ini karena pengeringan kulit buah naga terlalu singkat dan suhu yang digunakan juga rendah sehingga mengakibatkan kulit buah naga tidak kering dengan baik dan warna yang dihasilkan agak pucat, tidak sama dengan warna pada perlakuan yang menggunakan suhu $60^{\circ} \mathrm{C}$ waktu 12 jam yang memiliki warna cerah sehingga panelis lebih banyak menyukainya.

Tingkat kesukaan/penilaian panelis terhadap warna ini mendapatkan data yang berbeda-beda dan tidak stabil. Hal ini dikarenakan tidak semua orang menyukai warna yang berbeda-beda. Menurut Priatni dan Aulia (2015) dalam kulit buah naga terdapat pigmen betalain yang terdiri dari betasianin (memberikan warna merah keunguan) dan betaxanthin (memberikan warna kuning-oranye) yang dapat berperan sebagai antioksidan. Pigmen alami ini mudah terdegradasi, labil terhadap panas, dan memiliki stabilitas struktur yang rendah. Warna kulit buah naga sebelum dan setelah dikeringkan mengalami perubahan. Warna biasanya merupakan tanda kemasakan atau kerusakan dari makanan, seperti perlakuan pengeringan 
yang memungkinkan adanya perubahan warna (Meilgaard, 2000 dalam Naibaho, 2016). Warna makanan memiliki peranan utama dalam penampilan makanan, meskipun makanan tersebut lezat, tetapi bila penampilan tidak menarik waktu disajikan akan mengakibatkan selera orang yang akan memakannya menjadi hilang (Moehyi, 1992).

\section{Uji Organoleptic Aroma}

Aroma adalah reaksi dari makanan yang akan mempengaruhi konsumen sebelum konsumen menikmati makanan, konsumen dapat mencium makanan tersebut. Aroma juga merupakan salah satu komponen cita rasa makanan dan dapat menjadi penentu kelezatan makanan. Aroma buah-buahan disebabkan oleh berbagai ester yang bersifat volatil (tidak stabil) (Winarno, 1992). Berdasarkan hasil uji organoleptik aroma dari tingkat kesukaan (skala Hedonik) yang dipilih panelis (15 panelis). Panelis yang dipilih yaitu panelis semi terlatih. Panelis semi terlatih adalah panelis yang sudah pernah mendapatkan pelajaran tentang uji organoleptik.

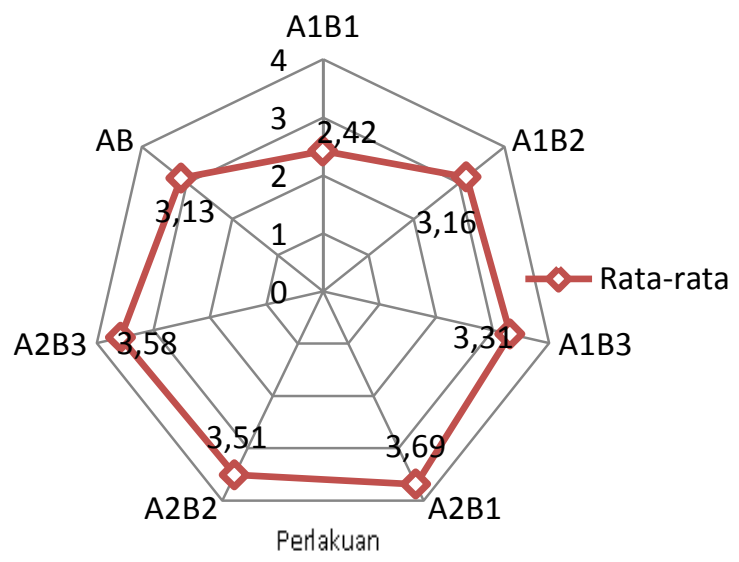

Gambar 4. Grafik Rata-Rata Penilaian Panelis Terhadap Aroma Minuman Kulit Buah Naga (Hylocereus costaricencis) dengan Beberapa Perlakuan setelah Dikeringkan Menggunakan Oven selama 6 Jam, 12 Jam dan 24 Jam serta Menggunakan Suhu $40^{\circ} \mathrm{C}$ dan $60^{\circ} \mathrm{C}$.

Gambar 4 menunjukkan rata-rata tingkat kesukaan panelis terhadap aroma minuman kulit buah naga yang telah diseduh yaitu berkisar antara 2,42-3,69 yang berarti tidak suka sampai dengan suka. Dari hasil tabel dan grafik diatas menunjukkan bahwa aroma yang paling disukai panelis dari hasil uji organoleptik yang dilakukan adalah pengeringan dengan suhu $60^{\circ} \mathrm{C}$ dan dengan waktu 6 jam dengan nilai 3,69. Pada pembuatan minuman kulit buah naga awalnya kulit buah naga yang belum dikeringkan tidak memiliki aroma, tetapi setelah dikeringkan dengan menggunakan perlakuan, minuman kulit buah naga menjadi memiliki aroma yang khas. Aroma yang dikeluarkan setiap makanan berbeda-beda. Selain itu, cara mengolah yang berbeda akan menimbulkan aroma yang berbeda pula (Moehyi, 1992).

Rata-rata tingkat kesukaan panelis terhadap aroma minuman kulit buah naga yang mendapat nilai terendah adalah perlakuan dengan menggunakan suhu pengeringan $40^{\circ} \mathrm{C}$ dan waktu 6 jam $(2,42)$. Jumlah komponen volatil yang dilepaskan oleh suatu produk akan dipengaruhi suhu dan komponen alaminya. Komponen aroma akan dikenali apabila berbentuk gas atau uap (Wulandari, 2016). Proses pengeringan merupakan salah satu peranan penting dalam daya simpan suatu bahan pangan, karena proses pengeringan dapat mempengaruhi penampakan, tekstur, aroma dan cita rasa pada bahan pangan (Wulandari, 2016). Uji organoleptik yang telah dilakukan mendapatkan nilai yang berbeda dari masing-masing panelis. Hal ini dikarenakan tingkat kesukaan masing-masing panelis terhadap aroma suatu bahan pangan akan berbeda. Meskipun mereka dapat mendeteksi, tetapi setiap individu memiliki kesukaan yang berlainan (Meilgaard, 2000 dalam Naibaho, 2016).

\section{Uji Organoleptik Rasa}

Rasa juga merupakan hal yang penting dalam suatu bahan pangan. Jika suatu bahan pangan tidak memiliki rasa yang khas pada suatu jenis makanan maka makanan tersebut tidak akan laku dipasaran. Rasa makanan merupakan faktor kedua yang mempengaruhi cita rasa makanan setelah penampilan makanan itu sendiri (Moehyi 1992). Berdasarkan hasil uji organoleptik rasa dari tingkat kesukaan (skala Hedonik) yang dipilih panelis (15 
panelis). Panelis yang dipilih yaitu panelis semi terlatih. Panelis semi terlatih adalah panelis yang sudah pernah mendapatkan pelajaran tentang uji organoleptik. Masingmasing perlakuan dan ulangan pada minuman kulit buah naga dapat dilihat pada gambar 5 .

Gambar 5 menunjukkan rata-rata tingkat kesukaan panelis terhadap rasa minuman kulit buah naga yang telah diseduh yaitu berkisar antara 2,13- 3,93 yang berarti tidak suka sampai dengan suka. Dari hasil tabel dan grafik diatas menunjukkan bahwa rasa yang paling disukai panelis dari hasil uji organoleptik yang dilakukan adalah pengeringan dengan suhu $60^{\circ} \mathrm{C}$ dan dengan waktu 12 jam dengan nilai 3,93. Hal ini sesuai dengan pendapat Meilgaard (2000) dalam Naibaho (2016), bahwa tingkat kematangan, keempukan atau kekenyalan makanan, kerenyahan makanan dan temperatur makanan akan mempengaruhi penilaian terhadap suatu bahan pangan.

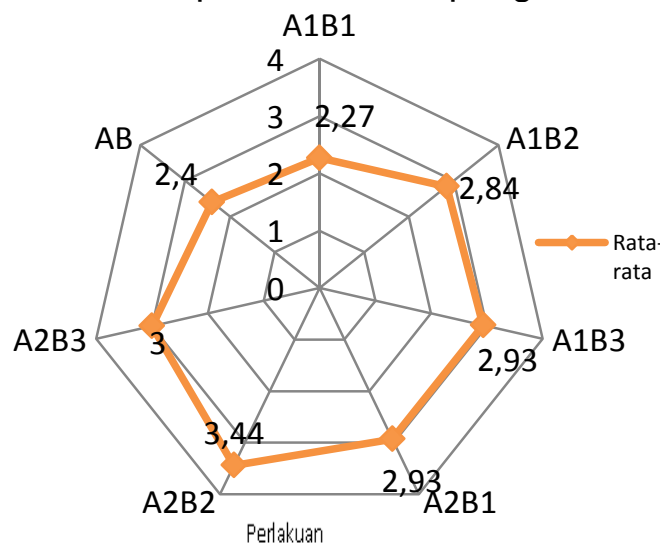

Gambar 5. Grafik Rata-Rata Penilaian Panelis terhadap Rasa Minuman Kulit Buah Naga (Hylocereus costaricencis) dengan Beberapa Perlakuan setelah Dikeringkan Menggunakan Oven selama 6 Jam, 12 Jam dan 24 Jam serta Menggunakan Suhu $40^{\circ} \mathrm{C}$ dan $60^{\circ} \mathrm{C}$.

Rata-rata kesukaan panelis terendah terhadap rasa minuman kulit buah naga terdapat pada perlakuan yang menggunakan suhu $40^{\circ} \mathrm{C}$ dengan waktu 6 jam $(2,13)$. Hal ini dikarenakan kulit buah naga kurang kering sehingga rasa dari minuman kulit buah naga pada perlakuan ini memiliki rasa yang agak sepat, sehingga panelis memberi nilai yang rendah. Hal ini didukung oleh Labuza
(1970) yang mengatakan bahwa suhu akan mempengaruhi proses pengeringan. Semakin rendah suhu yang diberikan maka proses pengeringan tidak akan maksimal dan akan mempengaruhi cita rasa suatu bahan pangan. Trisia, dkk (2016) juga mengatakan bahwa cita rasa makanan merupakan salah satu faktor yang mempengaruhi daya terima terhadap makanan yang disajikan. Cita rasa makanan mencakup dua aspek yaitu penampilan makanan sewaktu dihidangkan dan rasa makanan sewaktu dimakan. Kedua aspek itu sama pentingnya untuk diperhatikan agar betul-betul dapat menghasilkan makanan yang memuaskan.

\section{KESIMPULAN}

Hasil penelitian menunjukkan bahwa kadar air yang paling rendah didapatkan dari pengeringan dengan perlakuan menggunakan suhu $60^{\circ} \mathrm{C}$ dan waktu 24 jam yaitu $3,17 \%$. Uji organoleptik yang telah dilakukan terhadap minuman kulit buah naga ini mendapat nilai yang baik dari panelis. Perlakuan yang paling disukai panelis yaitu dengan pengeringan menggunakan suhu $60^{\circ} \mathrm{C}$ dan waktu 12 jam untuk warna yaitu mendapatkan nilai 3,82 (suka), aroma dengan nilai 3,51 (suka) dan rasa dengan nilai 3,44 (agak suka).

\section{DAFTAR PUSTAKA}

Kusumah dan Andarwulan. 1989. Prinsip Teknologi Pangan. Jakarta: Rajawali Press.

Labuza, T.P. 1970. Properties of water as related to the keeping quality of foods. Washington, DC,Proceedings of the Third International Congress of Food Science, IFT. Symposium on Physical and Chemical Properties of Foods. pp. 618-635.

Moehyi, S. 1992. Penyelenggara Makanan dan Jasa Boga. Bharata. Jakarta.

Naibaho, Hudaida, S., Hadi S., 2009. Studi Waktu dan Metode Blanching Terhadap Sifat Fisiko-Kimia Tepung Talas Belitung (Xanthosoma sagittifolium) 
Naibaho, A. 2016. Studi Penggunaan Minyak atsiri Daun Jeruk Purut (Citrus Hystrix DC) Terhadap Pengawetan Daging Ayam dalam Penyimpanan Suhu Dingin. Politeknik Pertanian Negeri Samarinda.

Putri. 2014. Uji Kalsium dan Organoleptik Minuman Kombinasi Daun Sirsak dan Kulit Buah Naga Merah Dengan Variasi Suhu Pengeringan. Universitas Muhammadiyah Surakarta.

Romadhon, S.A., Syahbuddin, dan P.H., Riyadi. 2014. Pengaruh Penambahan Telur Rajungan (Portunus Pelagicus) dengan Konsentrasi yang Berbeda Terhadap Kualitas Mie Basah. Universitas Diponegoro.

Trisia, N., L. Sitoayu, dan T.H. Pakpahan. 2016. Perbedaan Daya Terima Lauk hewani Berdasarkan Citarasa, Kebiasaan Makna dan Nafsu Makan di Berbagai Kelas Rawat Inap Pasien Beda Di RSUD Cengkareng. Universitas Esa Unggul.

Wahyuni, Rekna,.2010. Pemanfaatan dan Pengolahan Kulit Buah Naga Super Merah. Malang: Universitas Brawijaya. HIm 9

Winarno, F, G. 1992. Kimia Pangan Dan Gizi. Cetakan VI. Jakarta: PT Gramedia Pustaka Utama.

Wulandari, S. 2016. Citarasa dan Komponen Flavor Kopi Luwak Robusta In Vitro Akibat Perbedaan Konsentrasi Ragi dan Lama Fermentasi. Universitas Jember. 